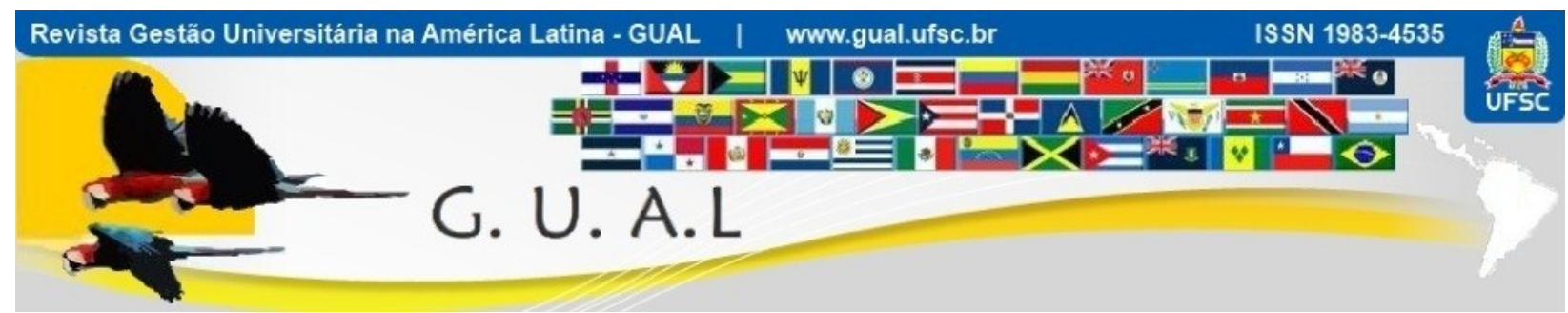

DOI: http://dx.doi.org/10.5007/1983-4535.2012v5n4p116

\title{
A UNIVERSIDADE ESTÁ CONTRIBUINDO PARA A IGUALDADE DE GÊNERO? \\ UM OLHAR SOBRE A PERCEPÇÃO DOS DOCENTES DE PÓS-GRADUAÇÃO
}

\section{THE UNIVERSITY IS CONTRIBUTING TO GENDER EQUALITY? A REFLECTION ON THE PERCEPTIONS OF POSTGRADUATION LECTURERS}

Susana Gauche Farber, Mestre Universidade do Vale do Itajaí - Univali susana.farber@yahoo.com.br

Miguel Angel Verdinelli, Doutor Universidade do Vale do Itajaí - Univali nupad@univali.br

Mehran Ramezanali, Mestre Universidade do Vale do Itajaí - Univali mehran@brturbo.com.br

Recebido em 16/novembro/2012

Aprovado em 07/dezembro/2012

Sistema de Avaliação: Double Blind Review

Esta obra está sob uma Licença Creative Commons Atribuição-Uso. 


\title{
A UNIVERSIDADE ESTÁ CONTRIBUINDO PARA A IGUALDADE DE GÊNERO? \\ UM OLHAR SOBRE A PERCEPÇÃO DOS DOCENTES DE PÓS-GRADUAÇÃO \\ DOI: http://dx.doi.org/10.5007/1983-4535.2012v5n4p116
}

\section{RESUMO}

O princípio da igualdade, fundamental aos direitos humanos, é sabidamente um pressuposto do desenvolvimento social e econômico com harmonia das nações. E, neste sentido, o papel das instituições deve ser bastante contributivo, destacando-se dentre elas a universidade, pois é ai que se formam cidadãos, profissionais e professores de todos os níveis da educação formal. Em face disto, o objetivo geral do artigo é analisar a percepção que têm da igualdade e desigualdade de gênero, na academia, os docentes que atuam em universidades comunitárias de Santa Catarina, em programas de pós-graduação stricto sensu acadêmicos. Para tanto o design da pesquisa foi um levantamento com sete professores de três cursos desta natureza. Cabe destacar que este trabalho representa uma parte de uma pesquisa maior. Os dados foram obtidos com entrevistas em profundidade e submetidos à análise do discurso. Os resultados demostram que há desigualdade nesse âmbito, mesmo que sútil ou invisivelmente. Associamse com isto comportamentos patriarcais, os que afetam e dificultam seu desempenho profissional. Os resultados respeito de suas visões sobre a universidade e sua contribuição para a igualdade, salientam quão importantes são estas instituições para o esclarecimento, criação de oportunidades e igualdade, bem como, para a promoção de mudanças.

Palavras-chave: Gênero. Igualdade. Desigualdade. Universidades.

\begin{abstract}
The principle of equality, vital to human rights, is known to be an assumption of social and economic development of nations in harmony. Thus, the role of the institutions should be fairly contributory. Specially, in the case of the university, since it is there that citizens, professionals and teachers are educated at all levels of formal education. Considering this context, the general objective of the present paper is to analyze the perceptions of lecturers working in universities of the state of Santa Catarina in Postgraduate studies in terms of equality and gender inequality in Academia. The research strategy was through personal semistructured interviews with seven teachers from three courses of this nature. It should be noticed that this work is part of a more comprehensive study. Data was obtained from indepth interviews through discourse analysis. The results showed that there is inequality in this context, even if subtle or invisible. Patriarchal behaviors are associated with this reality; they affect and hinder job performances. The findings related to their views about the university and its contribution to equality emphasize how important these institutions are for the clarification of ideas, creating opportunity and equality, as well as promoting changes.
\end{abstract}

Keywords: Gender. Equality. Inequality. Universities. 


\section{A UNIVERSIDADE ESTÁ CONTRIBUINDO PARA A IGUALDADE DE GÊNERO? \\ UM OLHAR SOBRE A PERCEPÇÃO DOS DOCENTES DE PÓS-GRADUAÇÃO \\ DOI: http://dx.doi.org/10.5007/1983-4535.2012v5n4p116}

\section{INTRODUÇÃO}

A relevância e a importância do tema da igualdade de gênero abrange o mundo. Há uma consciência global do valor da sua construção para o desenvolvimento social e econômico de um país. E, a partir desta constatação ações governamentais mundiais têm sido realizadas, as políticas públicas têm demonstrado sensibilidade e ações concretas sobre o tema. Os estudos perpassam pela forma que se dá as relações entre homens e mulheres. Relações estas que podem estar permeadas de poder resultando em desigualdades de gênero, o que fere um dos princípios básicos dos direitos humanos: a igualdade. $\mathrm{O}$ enfrentamento a tais assimetrias de gênero não deve ser tomado como uma meta tecnocrática, mas como um processo político que requer mudanças efetivas. Os estereótipos sobre mulheres e homens, os papéis esperados e as ideologias de gênero devem dar lugar ao reconhecimento do ser humano, de forma independente do seu sexo.

O gênero pode ser considerado sob a teoria do essencialíssimo ou do construtivismo social, sendo que este estudo baseia-se na perspectiva de gênero como uma construção, onde a identidade, os papéis e as ideologias são edificados a partir da socialização dos indivíduos.

Os diferentes papéis de gênero, padrões, normas sociais e expectativas sobre o que é adequado a homens e mulheres, afetam as aspirações, comportamentos, preferências e atuação na vida privada e pública, resultando em desigualdade e inequidade. Conformando ciclos que reproduzem essas assimetrias sociais e cujo rompimento se faz necessário em prol do desenvolvimento harmônico de toda nação.

Nesta mudança as instituições tem um papel relevante e dentre elas a universidade pode e deve atuar face seu grande compromisso com a sociedade, particularmente, por ser nela onde se formam os professores de todos os níveis da educação formal. Pois se deve considerar à educação protagonista para a construção da igualdade de gênero na sociedade. $\mathrm{O}$ acesso igualitário de homens e mulheres ao ensino universitário tem sido garantido assim como os processos seletivos do seu corpo docente, desenvolvidos com base no mérito, titulação e producão intelectual. Entretanto, será que a igualdade de gênero manifesta-se nas instituições de ensino superior? Em especial nos programas de pós-graduação stricto sensu acadêmicos, onde irão formar-se os professores dos futuros professores. O desenvolvimento e a manutenção da carreira de homens e mulheres nesse ponto nevrálgico da universidade serão igualitários? Haverá congruência entre discurso e prática nas estruturas burocráticas internas à instituição e nos órgãos reguladores? Enfim, muitos outros questionamentos poderiam ser 


\section{A UNIVERSIDADE ESTÁ CONTRIBUINDO PARA A IGUALDADE DE GÊNERO? \\ UM OLHAR SOBRE A PERCEPÇÃO DOS DOCENTES DE PÓS-GRADUAÇÃO \\ DOI: http://dx.doi.org/10.5007/1983-4535.2012v5n4p116}

feitos, porém no intuito de dar um primeiro passo o presente trabalho se direciona ao estudo da realidade no âmbito da pós-graduação stricto sensu, que por sua importância deveriam estar livres de desigualdades. Assim, o objetivo desta pesquisa é buscar a percepção dos professores e professoras que atuam em universidades privadas de Santa Catarina quanto à igualdade e desigualdade de gênero na academia.

\section{GÊNERO}

O surgimento de gênero está relacionado ao reconhecimento e à contestação social da desigualdade de direitos entre homens e mulheres. A disseminação do conceito de gênero a nível global e nas mais diversas ciências sociais surgiu pela sua associação aos movimentos feministas que questionavam o essencialíssimo das categorias homem e mulher (RODRIGUES, 2009). Esta pesquisa não abordará as teorias feministas, mas sim tomará como referência a perspectiva sociológica, onde gênero é considerado uma construção social e cultural. Ser homem ou mulher é resultado de um aprendizado que se inicia na família e continua em todas as instituições da sociedade. Os indivíduos com suas interações vão estabelecendo expectativas do que é socialmente acertado para um homem e para uma mulher e assim as ideologias de gênero vão se formando. Connell (2006) fala em rótulos, entendendo a masculinidade e a feminilidade como configurações das práticas sociais de gênero.

As desigualdades nas relações de gênero que aparecem na estrutura social, ora explicitamente e em outros momentos sorrateiramente, resultam das expectativas das identidades, dos papéis e das ideologias de gênero. Entende-se, portanto, que homens e mulheres são diferentes, mas esta diferença biológica não justifica as desigualdades que são construídas socialmente. Tais vieses são os que fazem do gênero um constructo a se estudar e explicar e não um fator explicativo. As igualdades e desigualdades, as diferenças, as equidades e inequidades, assim como as interações que ocorrem nas relações entre homens e mulheres, são alguns dos aspectos considerados nos estudos de gênero. Conforme assinala Connell (1995), assume-se que no sistema patriarcal existem dinâmicas de poder e relações sociais assimétricas entre homens e mulheres. Famílias, organizações, instituições e sociedades estão permeadas por estas relações que se traduzem em diversas formas de desigualdades, não somente, por exemplo, na representação dos gêneros, mas também nas posições ocupadas (NETTLES et al., 2000). 


\section{A UNIVERSIDADE ESTÁ CONTRIBUINDO PARA A IGUALDADE DE GÊNERO? \\ UM OLHAR SOBRE A PERCEPÇÃO DOS DOCENTES DE PÓS-GRADUAÇÃO \\ DOI: http://dx.doi.org/10.5007/1983-4535.2012v5n4p116}

\subsection{IGUALDADE E DESIGUALDADE DE GÊNERO}

A busca da igualdade de gênero tem sido amplamente reconhecida em todos os países como algo emergencial e necessário para o desenvolvimento social e econômico. A participação igualitária de homens e mulheres na vida civil, política, econômica, social e cultural constitui uma meta a ser alcançada no mundo. Políticas públicas mundiais estão se tornado mais sensíveis à questão e um conjunto de intenções, decisões, objetivos e medidas vem sendo adotadas pelos poderes públicos (BUSTELO, 2004). Muitas estratégias foram elencadas para atingir tal resultado, como a participação de mulheres nas tomadas de decisão em todos os órgãos públicos e políticos. Outras foram pontuais quanto ao mercado de trabalho, como a adoção de medidas a fim de solucionar a discriminação horizontal e vertical ou o incentivo às transformações na sua organização, a fim de garantir uma partilha equitativa das responsabilidades profissionais e familiares, permitindo conciliar a responsabilidade privada, profissional e social.

Entretanto, apesar da relevância da simetria entre os gêneros e dos esforços realizados, se percebe uma lacuna entre o discurso e a prática. As desigualdades e as inequidades ainda estão presentes e são bem representativas na vida social e profissional de homens e mulheres em todo mundo, sejam países desenvolvidos ou em desenvolvimento. Estas duas dimensões, o público e o privado, são chaves para a conceptualização das principais estruturas que contribuem, mantem e reproduzem a desigualdade de gênero. Elas estão interconectadas, formadas por normas, valores, instituições e organizações que reproduzem a desigualdade de gênero em cada uma das esferas (VERLOO e LOMBARDO, 2007).

Indícios do desequilíbrio nas relações de poder entre homens e mulheres são perceptíveis através de alguns indicadores, tais como: segregação de mercado, trabalho formal e informal, trabalho remunerado e não remunerado, disparidades salariais, acúmulo de bens, restrições na capacidade de decisão pública e privada, índices de violência doméstica, dentre outros.

Quanto à vida privada, as ideologias de gênero estabelecem como sendo somente da mulher as responsabilidades familiares domésticas. Apesar do aumento na participação de mulheres no mercado de trabalho, chegando hoje a mais de $40 \%$ da força de trabalho no mundo (WORLD BANK, 2011) e com um crescimento duas vezes mais rápido (MÓSESDÓTTIR, 2011), houve pouquíssimos homens assumindo a casa ao longo dos últimos anos (COVERMAN e SHELEY, 1986; SÁNCHEZ-HERRERO, 2008; SÁNCHEZ- 


\section{A UNIVERSIDADE ESTÁ CONTRIBUINDO PARA A IGUALDADE DE GÊNERO? \\ UM OLHAR SOBRE A PERCEPÇÃO DOS DOCENTES DE PÓS-GRADUAÇÃO \\ DOI: http://dx.doi.org/10.5007/1983-4535.2012v5n4p116}

HERRERO et al., 2009). Isto reflete no que Goetz (2003) chama de tripla jornada laboral feminina, ou triplo papel das mulheres: papel reprodutivo (criação e educação dos filhos); papel produtivo (trabalho remunerado) e o papel comunitário.

As mulheres para atuarem com bom êxito nos três papéis reduzem seu tempo de dedicação ao trabalho em função da família. O fato das mulheres não participarem de cargos de poder pode estar influenciado pela maternidade, constituindo um fator limitante para o avanço na carreira profissional. Uma hegemonia masculina foi incorporada ao trabalho e a família onde as próprias mulheres consentem e participam das regras colocadas (CONNELL, 1987; PÉTURSDÓTTIR, 2012). Pode-se dizer que a sociedade em geral não superou o progresso profissional das mulheres. Coates (2010) destaca que o conhecido fenômeno teto de vidro faz parte de politicas não oficiais nas organizações, conformando barreiras invisíveis, que não permitem perceber outros impedimentos para o avanço das carreiras de mulheres.

Os diferentes papéis de gênero, padrões, normas sociais e expectativas sobre o que é adequado a homens e mulheres, afetam as aspirações, comportamentos e preferências, o que conspira favoravelmente à segregação de mercado. Eagley (1987) identificou que homens e mulheres têm ocupado partes distintas do espaço econômico. Guetos de gênero na universidade continuam a existir, indicando uma preferência feminina por ciências humanas e saúde, enquanto a masculina é pelas ciências exatas e engenharias. Mas, cabe se perguntar: existe profissão para homens e mulheres? Simplesmente algumas premissas são assimiladas como naturais e podem distorcer a ontologia dos papéis do ser humano. Muitos questionamentos ainda não foram clarificados: Por que algumas pessoas se revestem do pensamento masculino e outras do feminino? Por que há falta da linearidade entre os sexos quando falamos de mercado de trabalho ou espaço acadêmico? Deve-se refletir com muita atenção porque ainda há âmbitos considerados masculinos e outros femininos na sociedade.

Porém, por causa do seu peso simbólico e da sua valoração social, a masculinidade passou a se constituir uma definição do humano, tornando-se um modelo ideal e referência de ser humano (AMIGOT LEACHE, 2011). Devido a sua neutralidade aparente mascara a discriminação que existe, tanto que até mesmo nas profissões, muitas vezes, não possuem a inflexão do gênero. No Brasil, esta realidade foi modificada logo da sanção pela Senhora Presidenta Dilma Rousseff da Lei No 12.605, de 3 de abril de 2012, que determina a utilização obrigatória da flexão de gênero para nomear a profissão e o grau em diplomas e 


\section{A UNIVERSIDADE ESTÁ CONTRIBUINDO PARA A IGUALDADE DE GÊNERO? \\ UM OLHAR SOBRE A PERCEPÇÃO DOS DOCENTES DE PÓS-GRADUAÇÃO \\ DOI: http://dx.doi.org/10.5007/1983-4535.2012v5n4p116}

certificados expedidos pelas instituições de ensino públicas e privadas. Permitindo, inclusive, às pessoas já diplomadas requerer a mudança no documento.

$\mathrm{Na}$ academia, Bailyn (2003) considera que tal suposta neutralidade resulta no atual modelo "masculino" das normativas ideais para a academia. Homens e mulheres serão bem sucedidos se admitirem e seguirem certas normas. Estes apontamentos levam a uma reflexão, que vai além da igualdade de oportunidade. Pois a mesma pode existir, porém não é justa se as restrições forem muito desiguais. Normalmente, encontramos restrições que diferem entre homens e mulheres. Portanto, uma situação equitativa deve implicar a igualdade de oportunidades e de restrições (BAILYN, 2003; RAPOPORT et al., 2002). Não observar este equilíbrio, é ignorar um problema que pode trazer consequências graves para a carreira. Outro aspecto importante da equidade de gênero é a integração do público com o privado. Isto é, ao invés de se separar a esfera pública, (trabalho econômico), da esfera privada (família, vida pessoal) se as considera de modo integrado. Esta atenção e valorização igualitária das duas esferas exercita a equidade. Contudo, exige reconsideração das práticas existentes para se ajustar à visão integrada.

\subsection{GÊNERO, UNIVERSIDADE E SOCIEDADE}

A universidade, é um ambiente particular, é uma das instituições que possui influência na sociedade. Representa um modelo, é uma referência, dissemina conhecimento e ao mesmo tempo reflete aspectos da realidade social, anunciando e antecipando mudanças que nela ocorrem. Como toda instituição, o ambiente universitário, desperta expectativas na sociedade quanto a sua atuação. Através do tripé: ensino, pesquisa e extensão a educação superior atinge a essência de sua missão. Ou seja, preparar os indivíduos quanto aos conhecimentos técnicos e saberes profissionais para atuarem no mercado de trabalho e formar a pessoa humana, integrando-a na sociedade como verdadeira cidadã.

A universidade, berço de novos conhecimentos, não pode apenas refletir a sociedade, sua missão é tornar-se indutora das mudanças necessárias para o avanço no sentido de uma sociedade equitativa (CULLEN, 2009), sendo prospectora e a protagonista. Nessa perspectiva, espera-se que a universidade promova iniciativas para o desenvolvimento humano, social, político e econômico. Para tanto deverá assumir um posicionamento quanto suas próprias políticas de gestão, as que necessitam estar alicerçadas em valores que reafirmem a democracia e os direitos humanos, o respeito pelas diferenças e especificidades de cada 


\section{A UNIVERSIDADE ESTÁ CONTRIBUINDO PARA A IGUALDADE DE GÊNERO? \\ UM OLHAR SOBRE A PERCEPÇÃO DOS DOCENTES DE PÓS-GRADUAÇÃO \\ DOI: http://dx.doi.org/10.5007/1983-4535.2012v5n4p116}

pessoa. A universidade deve ser fator de coesão da diversidade dos grupos humanos. Para Delors (1999), o princípio da equidade e da igualdade devem orientar as políticas das instituições de ensino superior.

Entretanto, pesquisas relacionando educação e igualdade ou desigualdades tem demostrado que apesar de serem supostos os princípios de igualdade para todos, a instituições de ensino podem estar utilizando mecanismos sutis de discriminação (BONDER, 1994). A universidade pode estar reproduzido o modelo patriarcal. Um olhar da perspectiva de gênero mais criterioso, em particular nas universidades que é aonde vão se formar os professores dos demais níveis, se faz necessário. O tema de gênero na educação deve ser abordado para promover uma reflexão crítica sobre as estruturas de poder que sustentam as diferenças sociais.

As disparidades podem emergir em todos os ambientes, inclusive nas universidades. Em geral, as instituições de ensino superior (IES) parecem um âmbito favorável à igualdade de gênero, devido a serem instituições chaves para o desenvolvimento social e econômico e por apresentarem critérios de acesso e promoção baseados no mérito e na capacidade. As IES, por sua natureza, deveriam estar livres de todo tipo de prejuízo aos indivíduos, contudo podem estar sendo cenários de distintas formas de discriminação de gênero (LÓPEZ et al., 2009).

As pesquisas que vem sendo realizadas com docentes universitários têm demonstrado que a igualdade entre professoras e professores está longe de ser uma realidade. Os estudos têm manifestado desigualdades, inequidades e desequilíbrios evidentes nas relações de gêneros em universidades de todos os países em que se dispõe de trabalhos dessa natureza, como pode ser visto nos artigos de Xie e Shauman (1998); Acker e Armeti (2004); Acker e Dillabough (2007); Hunter e Leahey (2010); Mósesdóttir (2011); Rolin e Vainio (2011); e, Kaufman e Chevan (2012), dentre outros.

Se a universidade desempenha o papel de um agente social que cria, transmite e dissemina conhecimentos, constituindo exemplo e referência para a sociedade, não se podem admitir disparidades neste âmbito. Para tanto, é necessário rever e avaliar suas atividades acadêmicas. Deste modo, a perspectiva masculina, que Beauvoir (1958) tinha caracterizado como uma referência universal, ainda pode ser reconhecida sua presencia no âmbito universitário. As IES deveriam estar ativas na busca de superação de tais desafios, contudo tem sido notório seu frequente afastamento dos problemas que envolvem a sociedade. Santos 


\section{A UNIVERSIDADE ESTÁ CONTRIBUINDO PARA A IGUALDADE DE GÊNERO? \\ UM OLHAR SOBRE A PERCEPÇÃO DOS DOCENTES DE PÓS-GRADUAÇÃO \\ DOI: http://dx.doi.org/10.5007/1983-4535.2012v5n4p116}

(1994) destacou o isolamento e a falta de comprometimento das instituições universitárias com os problemas mundiais onde quer que ocorram. Por ser uma instituição precisaria estar permanentemente em sintonia com a dinâmica social, sob pena de perder sua legitimidade e sua função (RICCI, 2009). Se a universidade se preocupa apenas em manter-se no mercado e não conversa com a sociedade, ela não merece ser chamada de instituição, pois passa a ser uma organização, como explica López-Segrera (2011):

[...] muitas das IES [...] têm perdido o caráter de instituições e tendem a se assemelhar às organizações do mundo dos negócios. [...] Isto implica numa perdida da sua função social, uma vez que a universidade deixa de ser um elo entre a educação e o desenvolvimento, entre o indivíduo e a sociedade. (LÓPEZ SEGRERA, 2011, p. 224). (Traduzido do espanhol).

As disparidades de gênero no trabalho acadêmico podem ser averiguadas através de indicadores como a representatividade de homens e mulheres nas diversas áreas do conhecimento, nas posições ocupadas na estrutura hierárquica das IES (reitorias, cargos de gestão, coordenações), na produtividade, nas atribuições (ensino, pesquisa, extensão), promoções acadêmicas, na disparidade salarial, entre outros. As próprias áreas de conhecimento podem estar evidenciando ou não os hiatos de gênero.

Realizando um levantamento do quadro de docentes na pós-graduação stricto sensu de administração e de turismo no Brasil, onde se formam professores que lecionarão ou lecionam ao nível de graduação em IES que, por sua vez, formam professores para atuarem nos demais níveis do ensino, notou-se que há desigualdade na representatividade dos gêneros num destes cursos. O corpo docente dos 53 mestrados e 31 doutorados de administração é formado por 701 professores e 322 professoras, enquanto no turismo a representação nos 4 mestrados é de 22 professoras e 20 professores. Em nível de gestão tem-se 35 coordenadores homens e 17 coordenadoras mulheres nos cursos de pós-graduação de administração. Já na área do turismo há equilíbrio, com duas coordenações atribuídas a cada gênero. Esta segregação ocupacional, ou seja, a proporção de homens e mulheres atuando em determinadas áreas da atividade profissional, é resultado das crenças sociais relativas ao que eles devem ou não fazer. São pressupostos baseados em experiências anteriores ou resultado da aprendizagem social. Rubin (1996) qualificou como tabu a divisão do trabalho em função do sexo. Um tabu contra a igualdade de gênero, dividindo homens e mulheres em duas categorias mutuamente exclusivas, exacerbando as diferenças biológicas. 


\section{A UNIVERSIDADE ESTÁ CONTRIBUINDO PARA A IGUALDADE DE GÊNERO? \\ UM OLHAR SOBRE A PERCEPÇÃO DOS DOCENTES DE PÓS-GRADUAÇÃO \\ DOI: http://dx.doi.org/10.5007/1983-4535.2012v5n4p116}

Quanto à perspectiva de gênero na academia, em especial na pós-graduação, uma das estratégias para mensurar os hiatos pode ser a produtividade dos docentes. A produtividade, além de ser um indicador de desempenho, pode ser levada em conta para aferir inequidades ou equidades de gênero na academia, se estabelecidos critérios pertinentes. Particularmente, porque diversas variáveis influenciam a produtividade. Dentre elas podem se mencionar o tempo de dedicação, o estilo profissional e científico, a área de pesquisa, os grupos de pesquisa em que se participa, a reputação da IES, os conselhos editoriais de onde se publica a produção acadêmica, assim como o modo em se desenvolve o equilíbrio entre família e carreira.

Apesar de o contexto acadêmico ter seus valores pautados na meritocracia, estudos sobre igualdade e desigualdade de gênero têm encontrado inconsistências nos modelos meritocráticos quanto à igualdade de oportunidades. Este sistema é considerado como um dos meios mais eficazes de assegurar os direitos humanos na sociedade. Entretanto, não é a realidade apresentada. Para Knights e Richards (2003) isto demanda reconhecer que não se pode simplesmente universalizar o conceito de mérito, mas deve-se situar dentro do contexto da sua utilização. Por sua parte, é importante reconhecer a tendência da meritocracia na academia pode ter concepções masculinas. Inequidade meritocrática pode diminuir o desenvolvimento da carreira, a promoção a cargos e a própria representatividade da equipe docente. Estudos para saber em que medida o sistema meritocrático reflete e reproduz a dominação dos valores masculinos e até onde as práticas servem para sustentar as desigualdades entre homens e mulheres nas universidades, é algo relevante não somente para a comunidade acadêmica, mas para a sociedade e geral.

A academia pode e deve ajudar reverter à desigualdade de gênero, sendo para isto necessário avaliar como o sistema está implantado. Todas as organizações tem sua parcela de contribuição na busca pela igualdade e a parte que lhes cabe às IES é muito significativa, pois haverá de influenciar todas as organizações. Cabe refletir se as estruturas burocráticas estão sendo, como apresentado no estudo de Bird (2011), incongruentes no relativo à igualdade e equidade desde a perspectiva de gênero.

\section{DELINEAMENTO DA PESQUISA}

O presente estudo se caracteriza como teórico-empírico. Autores como Pope e Mays (1995) recomendam a adoção dos métodos qualitativos, visto que eles proporcionam uma 


\section{A UNIVERSIDADE ESTÁ CONTRIBUINDO PARA A IGUALDADE DE GÊNERO? \\ UM OLHAR SOBRE A PERCEPÇÃO DOS DOCENTES DE PÓS-GRADUAÇÃO \\ DOI: http://dx.doi.org/10.5007/1983-4535.2012v5n4p116}

melhor compreensão dos fenômenos ao associar procedimentos de cunho racional e intuitivo, imperativos na exploração de um assunto. $\mathrm{O}$ método que melhor coaduna com o objetivo proposto é a Análise do Discurso, onde se aliam o aspecto social e o histórico. Ou seja, para compreender o sentido de um discurso, deve-se observar o interlocutor, o lugar de onde fala, a imagem que faz de si, do outro e do assunto que está sendo tratado. A ideologia, a posição social e as relações de poder são expressas através de um discurso.

A análise por ser interpretativa, não pode ser reduzida a uma sequência de procedimentos aplicados de forma mecânica (BILLING, 1991). O pesquisador é identificado por Patton (2002) como um bricoleur capaz de manejar distintas teorias, métodos e técnicas e construir com certa diversidade em uma linha de investigação unitária e dialética (fenômeno investigado e investigador).

Há uma pluralidade de correntes compondo esta metodologia, dentre estas, análise do discurso, análise crítica do discurso e análise sociológica do discurso. Considera-se uma abordagem transdisciplinar, desenvolvida e utilizada por várias disciplinas das ciências humanas e sociais (GODOI et al., 2006). Segundo Rueda (2003) para Focault um discurso é algo mais que a fala, algo superior a um conjunto de enunciados. Discurso é uma prática. Práticas sociais, não somente linguísticas, mas sim constitutivas de um dado contexto histórico.

Deste modo, o discurso, além de ser um conjunto de enunciados ditos efetivamente por um locutor, pode ser entendido como um conjunto de construções que explicam sua produção a partir de uma posição social e ideológica (RUEDA, 2003). Tais enunciados sociais muitas vezes são cristalizados e mantidos nos discursos. Para Rueda (2003), há uma grande importância da dimensão histórica dos fenômenos e das "falas" sociais, no sentido de compreender porque e como, determinado fenômeno tenha se tornado óbvio na opinião pública, nos discursos sociais dominantes.

Estudos iniciais de Ibañez (1979), e outros mais recentes como os de Orti (1989) e de Alonso (1998), diferenciaram os três níveis do discurso. No primeiro nível, está a dimensão mais denotativa e manifesta no texto. O próximo nível seria a análise estrutural e o subsequente é a dimensão pragmática. $\mathrm{O}$ trabalho de leitura busca superar as opiniões, os argumentos, que parecem ser banais e óbvios, a relação entre o manifesto e o latente, uma relação constante entre a análise e a interpretação (CONDE, 2009). Como Callejo (2001) reconhece o importante de um texto, na maioria das vezes, não é dito. A hermenêutica é 
realizada nas ressonâncias do diálogo, associando o dito e o não dito, na transcendência da literalidade.

No desenvolvimento deste trabalho o ambiente de pesquisa foi composto por três universidades comunitárias do sistema ACAFE (Associação Catarinense de Fundações Educacionais). A análise discursiva tomou como objeto a transcrição das entrevistas em profundidade com professores e professoras que atuam nos programas de pós-graduação stricto sensu da área de Ciências Sociais Aplicadas. A amostra dos sujeitos participantes das entrevistas foi definida por conveniência. Foram escolhidos professores pesquisadores com mais de dez anos de atuação na pós-graduação stricto sensu. A amostra também devia contemplar homens e mulheres que tenham exercido ou estejam exercendo cargo de coordenação e que nunca tiveram essa função no curso. Participaram da pesquisa sete atores sociais com os critérios definidos.

Quatro dos entrevistados já atuaram ou atuam como coordenadores dos programas. Justifica-se a escolha destes critérios para os respondentes por possuírem uma trajetória na carreira universitária e, certamente, podendo revelar situações vividas que contribuam para o objetivo deste estudo. Procurou-se, então, compreender as preocupações dos atores sociais tais quais elas são vividas no cotidiano, que, conforme salienta Soulet (2006), é apropriadamente resgatado pela pesquisa qualitativa. Para este artigo se fez o recorte com cinco dos entrevistados.

\section{ANÁLISE E DISCUSÃO DOS DADOS}

\subsection{DISCURSO SOBRE A IMPORTÂNCIA DA UNIVERSIDADE}

Na busca de compreensão sobre o fenômeno consideram-se seguidamente os discursos dos entrevistados respeito de suas visões sobre a universidade e sua contribuição para a igualdade.

\section{Entrevistada 1 (E1):}

... a universidade tem sem dúvida aberto caminhos para a profissionalização mais respeitosa e mais digna para a mulher. Sendo que, ainda afirmo, se tiver dois concorrentes com a mesma titulação e com uma produção semelhante, o homem é o escolhido. A escolha ainda é tendenciosa.

A entrevistada destaca como o ensino superior tem possibilitado a consecução de uma vida mais justa para mulher, mas seu discurso deixa transparecer que em um processo de 


\section{A UNIVERSIDADE ESTÁ CONTRIBUINDO PARA A IGUALDADE DE GÊNERO? \\ UM OLHAR SOBRE A PERCEPÇÃO DOS DOCENTES DE PÓS-GRADUAÇÃO \\ DOI: http://dx.doi.org/10.5007/1983-4535.2012v5n4p116}

seleção a universidade ainda é tendenciosa, privilegiando o sexo masculino. Cabe ressaltar que a IES à qual se refere $E 1$ é uma instituição privada, que realiza processos seletivos de docentes e não concursos, como as IES públicas.

\section{Entrevistado 2 (E2):}

... a universidade é PhD, a expertise da universidade é justamente contribuir para a construção da igualdade de gênero.

\section{Entrevistado 3 (E3):}

... a universidade é uma alternativa sim, é uma oportunidade. Quem está na academia tem uma educação seletiva, uma condição privilegiada para um entendimento maior quanto a igualdade.

Os relatos de $E 2$ e $E 3$ salientam quão importantes são as IES para o esclarecimento, a criação de oportunidades e o entendimento da igualdade de gênero. Estes atores sociais da pesquisa partem do princípio que o fato das pessoas estarem inseridas na academia, ao receberem uma educação seletiva, devem estar cientes da importância da igualdade de gênero no mundo. A pessoa sai diferente de quando entrou da universidade, pois nela não só se formam profissionais, mas também cidadãos. Os quais devem adquirir, como afirma Carbonari (2011), as competências necessárias que lhes permitam participar da vida coletiva de forma consciente. E, ainda, questionar legalmente as injustiças sociais.

A teoria e a prática da universidade devem estar muito claras e precisas na direção que se quer ir, implementando mudanças contributivas para o bem-estar e a justiça social. $\mathrm{O}$ presente e o futuro de uma sociedade, assim como do mundo, passa pela educação. Como se expressa no preâmbulo da Declaração Mundial sobre a Educação Superior no Século XXI da Organização das Nações Unidas (ONU, 1998): “Convencidos do que a educação é um dos pilares fundamentais dos direitos humanos, a democracia, o desenvolvimento sustentado e a paz".

\subsection{DISCURSO SOBRE A UNIVERSIDADE E GÊNERO}

\section{Entrevistada 1 (E1):}

...eu percebo muita diferença entre determinados cursos. Há cursos eminentemente voltados para profissionais femininas como a educação e outros para profissionais homens como a administração, economia, ciências contábeis, engenharias, medicina, odontologia. Há uma separação muito 


\section{A UNIVERSIDADE ESTÁ CONTRIBUINDO PARA A IGUALDADE DE GÊNERO? \\ UM OLHAR SOBRE A PERCEPÇÃO DOS DOCENTES DE PÓS-GRADUAÇÃO \\ DOI: http://dx.doi.org/10.5007/1983-4535.2012v5n4p116}

explicita da escolha profissional de cada curso. É priorizado a figura masculina para alguns cursos e feminina para outros.

A entrevistada busca em seu discurso comprovar a segregação das áreas. Ainda deixa transparecer em sua análise sobre o fenômeno, a influência dos estereótipos criados na sociedade quanto às escolhas profissionais realizadas. Os indivíduos são influenciados em suas escolhas pelo o que a sociedade espera. As ideologias de gênero contribuem substancialmente para a escolha profissional.

O discurso de $E 3$ corrobora o dito pela $E 1$ quando expressa:

...acredito que sim, mas não em todas as áreas, por exemplo, na nossa, em ciências sociais aplicadas, não acontece. Acho que somente nas engenharias, ciências naturais devido à tradição. Acredito que nestas áreas há feudos. [...] estes feudos já foram bem mais fortes, principalmente na década de 70 quando me formei.

A alocução deste entrevistado é pontual quanto à desigualdade, afirmando que acontece somente em algumas áreas específicas. Destaca ainda que houve períodos em que a segregação foi bem mais forte. Porém na administração, nas ciências sociais aplicadas, quando observamos a representatividade do corpo docente dos programas stricto sensu e nos cargos de coordenação destes cursos, é nítida a segregação pela área do conhecimento.

\section{Entrevistado 2 (E2):}

...acredito que muito pouca segregação exista. A segregação que existiu é consequência de pesquisadores mais antigos, onde o departamento ainda continua com perfil antigo. Por exemplo, o profissional da área da informática. $O$ meu departamento tem trinta professores, dos trinta professores tem uma mulher. Continua homens, mas se vir mais mulheres eu tenho certeza que ninguém irá impedi-la. Acredito que não são os homens que ajudam a segregar, mas sim o próprio mercado. O mercado ainda forma muitos profissionais com perfil homem para esta área, o da ciência da computação.

Este pesquisado em seu primeiro discurso expressa o sentimento e a verbalização de que a segregação é a minoria hoje. Contudo, dá um depoimento real e preocupante quanto a sua área de atuação, a Tecnologia da Informação. O interessante é como E2 frisa que a mulher não iria ser impedida ou discriminada se buscasse atuar em sua equipe. Pode-se perguntar: então porque persiste tal divisão? O próprio autor do discurso revela alguns motivos em sua fala: o mercado ainda forma muitos homens nesta área. Duas leituras podem-se extrair desta 


\section{A UNIVERSIDADE ESTÁ CONTRIBUINDO PARA A IGUALDADE DE GÊNERO? \\ UM OLHAR SOBRE A PERCEPÇÃO DOS DOCENTES DE PÓS-GRADUAÇÃO \\ DOI: http://dx.doi.org/10.5007/1983-4535.2012v5n4p116}

afirmação: o mercado de trabalho está aceitando mais homens que mulheres nesta área? Ou as mulheres não têm buscado se formar nesta área?

Todas estas duas suposições podem estar corretas. E ambas tem a mesma origem os estereótipos repercutindo na segregação do trabalho. Como argumenta Rimashevskaia (2008) os estereótipos de gênero não são tão inocentes como parecem a simples vista. Estendem-se além das violações da igualdade de direitos e oportunidades. Para a sociedade ainda há trabalhos somente para homens e somente para mulheres e tais expectativas criadas pela sociedade estão inferindo nas escolhas dos indivíduos.

Continuando seu depoimento, E2 afirma:

...Já se é sistema de informação, já está meio a meio, veio mudando a uns 10 anos. As mulheres já entendem que podem programar. As meninas podem programar tanto quanto os homens. O que tem acontecido é as empresas preferirem homens quando o cargo exige disponibilidade para viagens. $O$ homem sai na segunda e volta no domingo e não precisa justificar em casa. Enquanto que a mulher...

Mesmo em áreas na qual ela já foi aceita parece que há certo tabu quanto assumir as atribuições do respectivo cargo. O discurso reflete o difícil que é para a sociedade entender que a mulher também pode realizar certas ações, por exemplo, que o fato de viajar nem sempre irá se configurar como um problema.

Seguidamente E2 expressa que:

...olhando outras profissões, pensando na ciência da computação, nas engenharias, dá impressão que o mercado ainda diz "eu prefiro ter um profissional homem". [...] dentro da IES não, isto não acontece na educação, não vejo isto no mestrado, aqui nós homens somos em números menores. Não dá é para deixá-las sozinhas falam demais e as coisas não acontecem. Na academia não vejo segregação, somente lá fora no mercado.

Evidentemente igualdade e equidade de gênero não representa excluir o homem, não é deixar a mulher sozinha. É sim, construir as mesmas condições, trabalhar em conjunto, complementar as diferenças na busca da excelência na gestão da IES, no ensino, na pesquisa, na extensão e, principalmente, no resultado: a formação de profissionais com consciência da necessidade de sermos todos cidadãos, com direitos iguais.

O trabalho em conjunto e a complementaridade foi ressaltada no discurso de $E$ 1, como se mostra a seguir: 


\section{A UNIVERSIDADE ESTÁ CONTRIBUINDO PARA A IGUALDADE DE GÊNERO? \\ UM OLHAR SOBRE A PERCEPÇÃO DOS DOCENTES DE PÓS-GRADUAÇÃO \\ DOI: http://dx.doi.org/10.5007/1983-4535.2012v5n4p116}

...ainda falta bastante para a igualdade. Mas se nós chegarmos a uma igualdade muito grande também a graça de algumas coisas caem por terra, eu acho que o olhar deve ser de complementaridade. Esta possibilidade de nós olharmos juntos um homem e uma mulher, olhar para um mesmo objeto e chegar a um acordo é o ideal. E não que eu vou olhar igual a ele e viceversa, mas que ambos possam acrescentar e chegar a uma terceira coisa.

As diferenças são naturais e a diversidade de olhares traz riqueza, entendimento. $\mathrm{O}$ que é intolerável é a injustiça pelas diferenças e diversidades. Com a equidade de gênero temse unidade na pluralidade, uma complementariedade nas diferenças e nas diversidades. $\mathrm{O}$ ser homem e o ser mulher divergem em sua essência ontológica, porém, o fazer, ou seja, as atividades, serviços, trabalhos, profissões, organizações, instituições, não podem ser rotulados, estereotipados com miopias que existem e se recriam na sociedade. E a universidade que é formadora de consciência, de visões, deve-se fazer presente nesta construção de neutralidade dos papéis de gênero.

\section{Entrevistado 3 (E3):}

...me custa acreditar que no século XXI haja desigualdade. Acredito sim em embates políticos, ideológicos, interesses econômicos, vaidades e egocentrismo inseridos no ambiente acadêmico.

Mas a questão de desigualdade é evidente, como o próprio E3 disse num outro momento de seu discurso. Pode ser difícil acreditar que exista desde uma concepção masculina.

\section{Entrevistado 2 (E2):}

...não existe uma igualdade. Existe uma desigualdade. As pessoas do sexo masculino tem um desenvolvimento maior, e tem vantagens. $O$ mundo ainda é machista. Muitos homens ainda não ajudam nos afazeres domésticos, com medo de serem diminuídos. Isto prejudica as mulheres. Elas conseguiram a liberdade, mas na verdade não conseguiram. Elas conseguiram cortar alguns laços, mas a carga aumentou.

O entrevistado é categórico ao afirmar a desigualdade. Porque o mundo ainda é machista, não justifica que as IES devam ser. Que se corrobore ainda em algum país o que Osborn et al. (2000) sustentaram no seu artigo, que as mulheres na ciência passaram da exclusão à segregação. Pelo contrário, aqui está a missão da universidade, eliminar essas afrontas e contribuir à transformação do mundo, para que seja melhor. Conscientizar e ajudar 


\section{A UNIVERSIDADE ESTÁ CONTRIBUINDO PARA A IGUALDADE DE GÊNERO? \\ UM OLHAR SOBRE A PERCEPÇÃO DOS DOCENTES DE PÓS-GRADUAÇÃO \\ DOI: http://dx.doi.org/10.5007/1983-4535.2012v5n4p116}

a promover a igualdade, numa sociedade com ideologias de gênero reformadas, com uma visão de neutralidade e de equidade.

Mudanças nas atividades das professoras na academia foram relatadas no depoimento de E4, como se pode observar:

....antes elas não podiam pesquisar, agora podem. Elas fazem pesquisa, participam de bancas, todas as atividades que os homens fazem elas querem fazer. Agora, de alguma forma, como coordenador vejo que elas produzem mais que os homens, por elas serem mais organizadas, elas conseguem se coordenar mais e usam mais o planejamento estratégico.

Desprende-se deste depoimento o esforço da mulher para se estabelecer e afirmar no seu trabalho. Há uma aparente busca para provar à sociedade que é tão competente quanto o homem e, para tanto se sobrecarrega para manter o equilíbrio entre trabalho e família, o que configura em um verdadeiro malabarismo (GAUCHE FARBER, 2010). Na progressão na carreira suas condições são bem mais difíceis e muitas barreiras precisam ser superadas. Muitas vezes, pode custar o lazer e o descanso delas (SÁNCHEZ-HERRERO, 2008).

$\mathrm{Na}$ continuação da entrevista de E4, se confirma não apenas a maior jornada laboral feminina, mas também a flagrante desigualdade:

...ela chega em casa, e tem que dar conta de muitas outras atividades, tem que ajudar filhos nos deveres, preparar alimentação, enquanto ele vai ler e pesquisar. Existe uma desigualdade injusta. Deveria inclusive ter uma escala entre os casais para os deveres do lar. Esta escala nem deveria ser feita em PDCA (Plan, do, check, action), mas naturalmente.

O depoimento dá ainda uma ideia de como o esposo poderia programar a cooperação nas tarefas a casa e assim diminuir a sobrecarga da esposa e mãe, que também exerce uma profissão. Entretanto, ao invés de ter esta escala entre os casais, isso deveria se construir num valor natural para o dia a dia da vida de um casal, como resultado de consciência da equidade de gênero.

E4 continua sua entrevista dizendo:

...eu vejo como desigual e prejudicial para a mulher por um lado e por outro lado, vejo que ela aproveita todo este esforço e acaba superando e produzindo mais que alguns homens. Ela se esforça e atinge a meta que tem que ser cumprida. 


\section{A UNIVERSIDADE ESTÁ CONTRIBUINDO PARA A IGUALDADE DE GÊNERO? \\ UM OLHAR SOBRE A PERCEPÇÃO DOS DOCENTES DE PÓS-GRADUAÇÃO \\ DOI: http://dx.doi.org/10.5007/1983-4535.2012v5n4p116}

E isso às vezes custa muito caro para as mulheres e, com frequência, acaba afetando a saúde. Ao querer participar do mercado de trabalho, às vezes, se desgastem ao limite no intuito de dar conta das metas do trabalho e da família.

\section{Entrevistado 2 (E2):}

...aquelas que estão aqui na universidade e não tem filhos, ou os filhos já são adultos, estas se comportam igualmente aos homens, tanto na produtividade quanto em assumir cargos de gestão. Agora, aquelas que têm filhos entre zero e quinze anos evitam assumir cargos de gestão.

A mulher é tão competente quanto o homem. Inclusive, a pesquisa de Blum (1997) confirma que ela reage à situação social que lhe é imposta. Se seu cargo exigir atitudes mais agressivas, vai desenvolver tal comportamento. Homem e mulher, um não é mais do que o outro, basta dar igualdade de oportunidade e equidade de condições que a visibilidade da competência emana. Este depoimento mostra que com a igualdade de condições, há uma igualdade de comportamento, produtividade e gestão.

O entrevistado levanta uma questão muito relevante, o posicionamento da própria mulher em postergar o assumir cargos de gestão enquanto os filhos tem um maior grau de dependência. Muitas vezes, a leitura que se faz coloca às mulheres como não tendo oportunidade de alcançarem os cargos de poder, mas na visão de $E 4$ isto é, em determinadas circunstâncias, uma opção delas.

\section{Entrevistada 4 (E4):}

...Tem algumas situações que a gente percebe que existe um certo grau de preconceito, por exemplo: cargos dentro das instituições representativas, ai existe. Porque que existe? Ai a gente percebe se pegar os presidentes da Anpad, (Associação Nacional de Pós-graduação e Pesquisa em Administração), os coordenadores de sessão da Capes (Coordenação de Aperfeiçoamento de Pessoal de Nivel Superior), coordenadores de áreas da $\mathrm{CNPq}$ (Coordenação de Aperfeiçoamento de Pessoal de Nivel Superior), não é que não exista mulheres, existe. Mas presidência, vice presidência é novidade a mulher exercer algum tipo de cargo.

A entrevistada depõe sobre a desigualdade efetiva nas representatividades dos órgãos superiores da área. Poderia se repetir a sua pergunta: "Por que existe?" E se bem ela não responde, exemplifica a inequidade daqueles órgãos, o que representa ao setor e dissemina os conhecimentos (Anpad), o que regula aos cursos de pós-graduação (Capes) e o que financiam às pesquisas e aos pesquisadores $(\mathrm{CNPq})$. 


\section{Entrevistado 5 (E5):}

...eu vejo que tem diferença. Primeiro, dependendo das áreas tem super representatividade das mulheres dentro da academia. [...] Por exemplo, no meu departamento de economia você vê uma predominância de homens. Mas talvez isso seja relacionado ao curso. Na administração acho que está um pouco próximo assim. Mas são duas coisas: quanto a representatividade (nos cargos de gestão), acho que há uma baixa representatividade que não corresponde a uma igualdade de representações...

O discurso de E5 traz a tona algo que pode mascarar a real situação da mulher nas universidades. Por um lado há de se considerar o acesso ao ensino superior e nisso realmente não se vem diferenças de gênero. No total geral, cada vez há um número maior de ingressantes do gênero feminino, superando em muitas IES a quantidade de homens, mas na atividade docente é como o entrevistado confirma, tem diferenças. As representações não correspondem a uma igualdade.

\section{CONSIDERAÇÕES FINAIS}

A igualdade segundo o discurso de docentes do ambiente de trabalho que se estudou, os cursos de pós-graduação stricto sensu acadêmicos, é algo ainda distante. Demonstra-se, pelas alocuções dos atores sociais envolvidos, que no âmbito privado a desigualdade é mais evidente, entretanto isto se reflete no espaço público. A redistribuição de responsabilidades econômicas entre homens e mulheres não foi acompanhada de mudanças nos encargos domésticos (CONNELL, 2006). E, a assimilação do homem quanto ao seu papel esponsal e de pai é necessária e indispensável. Impressiona que ainda hoje se tenha uma "consciência social" tão cristalizada de que o papel da família é exclusividade da mulher. Isto é um fator limitante. A própria maternidade, fato natural, é vista como uma variável que está associada significativamente à atuação e promoção das mulheres no mercado de trabalho, afetando seu desempenho.

Nas relações de gênero, especialmente quanto aos papéis estereotipados pode estar havendo certo consentimento por parte das mulheres. Há uma hegemonia masculina que se perpetua. Em virtude desta verificação é importante destacar o valor do posicionamento das mulheres respeito à igualdade e equidade de suas funções. Homens e mulheres devem ser protagonistas e não vítimas. Contudo, um peso maior deveria ser dado à mulher como agente deste processo, considerando que homens estão em uma posição de privilégio. 


\section{A UNIVERSIDADE ESTÁ CONTRIBUINDO PARA A IGUALDADE DE GÊNERO? \\ UM OLHAR SOBRE A PERCEPÇÃO DOS DOCENTES DE PÓS-GRADUAÇÃO \\ DOI: http://dx.doi.org/10.5007/1983-4535.2012v5n4p116}

Nota-se nesta pesquisa de quão imbuída está a sociedade pelas regras patriarcais impostas. Os âmbitos privados e públicos ainda estão dimensionados como distintos e tal divisão prejudica a construção da igualdade, pois desconsidera e maquia as desvantagens ou vantagens. Os atores sociais deste estudo reconhecem e reforçam que as condições de atuação de homens e mulheres no mercado de trabalho são desiguais. Mas há consciência e reconhecimento que elas são tão competentes quanto eles em condições de igualdade de oportunidade e de equidade.

Deve-se ter um cuidadoso olhar sobre a representatividade das professoras nos cargos de gestão. A oportunidade, em alguns casos, está sendo dada. Contudo, o posicionamento em postergar a ocupação dos cargos, enquanto os filhos tem maior dependência, pode ser opção delas mesmas. Este fato reforça como a desigualdade no âmbito privado direciona e influência as escolhas e o trabalho.

Os estereótipos de gênero não são tão inocentes como parecem a primeira vista (Rimashevskaia, 2008), estão tão arraigados que refletem clara segregação nas diversas áreas do conhecimento, ainda que ,atualmente, em menor proporção. Para a sociedade há trabalhos somente para homens e somente para mulheres. Há áreas identificadas neste estudo, como as ciências da computação, que a segregação chega a ser preocupante. Nas ciências sociais aplicadas, quando observamos a representatividade do corpo docente dos programas stricto sensu e nos cargos de coordenação dos cursos de Administração do Brasil, é nítida a segregação. Alguns fatores podem ser elencados para justificar tal realidade, entre eles: as ideologias de gênero, que podem contribuir para a escolha profissional; o processo seletivo de ingresso na carreira docente, que embora promova a igualdade de oportunidade pode estar privilegiando o sexo masculino; e, as condições de produção e produtividade acadêmica.

Pode-se afirmar que a universidade tem evoluído no que diz respeito à igualdade de gênero, por exemplo, não há diferença salarial entre professores e professoras desenvolvendo a mesma atividade. No entanto, sua representatividade no corpo docente e, com maior visibilidade, nos cargos de gestão é notória. Por outro lado, a inequidade manifesta-se em diversos aspectos como ocorre na falta de um tratamento diferenciado na avaliação de sua produtividade intelectual, mensurada pelas publicações produzidas, no período da maternidade. As universidades, embora responsáveis pela formação de cidadãos e promotora de mudanças, apresentam sinais de desigualdades. 
Indivíduos são diferentes, homens e mulheres podem possuir diferenças, entretanto tais distinções não podem refletir desigualdade e inequidade. Tais diferenças são motivos fortes para que haja complementariedade tanto na vida pública quanto na vida privada. A diversidade de olhares é o que enriquece. E a universidade que é formadora de consciência, de visões, deve-se fazer presente nesta construção de neutralidade das identidades, dos papéis e ideologias de gênero.

A real situação das mulheres nas universidades pode estar sutilmente disfarçada. Há de se considerar que no acesso ao ensino superior não se veem diferenças. Percebe-se que há um número maior de ingressantes do gênero feminino, superando em muitas IES a quantidade de homens, mas na atividade docente nos programas de pós-graduação em Administração as diferenças são bem representativas e não correspondem a uma igualdade.

A questão de gênero não é algo explicativo e sim um fator a se explicar. Tanto a dimensão pública quanto privada precisam de pesquisas e reflexão, para assim construir a igualdade de gênero.

\section{REFERÊNCIAS}

ACKER, S.; ARMETI, C. Sleepless in academia. Gender and Education, v. 16, n.1, p. 3-24, 2004.

ACKER, S.; DILLABOUGH, J.-A. Women 'learning to labour' in the 'male emporium': exploring gendered work in teacher education. Gender and Education, v. 19, n.3, p.297-316, 2007.

ALONSO, L.E. La Mirada Cualitativa en Sociología. Madrid: Fundamentos, 1998. AMIGOT LEACHE, P. Incierta Feminidad, Incierta Masculinidad La Configuración Social de Las Identidades de Género. Clínica y Análisis Grupal, v. 1, n. 2, p. 175-192, 2011.

BAILYN, L. Academic Careers and Gender Equity: Lessons Learned from MIT. Gender, Work and Organization, v.10, n.2, p. 137-153, 2003.

BEAUVOIR, S. El segundo sexo. Buenos Aires: Siglo XX, 1958.

BILLING, M. Rhetorical and discoursive analysis: how families talk about the royal family. In: BRANDÃO, H.H.N. Introdução à analise do discurso. Campinas: Unicamp, 1991.

BIRD, S. R. Unsettling universities' incongruous gendered bureaucratic structures a casestudy approach. Gender, Work and Organization, v. 18, n. 2, p. 202-230, 2011.

BLUM, R. W. Risco e resiliência: Sumário para desenvolvimento de um programa.

Adolescência Latino-Americana, n.1, p.16-19,1997. 
BONDER, G. Mujer y educación en América Latina: hacia la igualdad de oportunidades. Revista Iberoamericana de Educación, n.6, p.9-48, 1994.

BUSTELO, María. La evaluación de las políticas de género en España. Madrid: Ediciones La Catarata, 2004.

CALLEJO, J. El grupo de discusión: introducción a una práctica de investigación. Barcelona: Ariel, 2001

CARBONARI, M. E. E. Gestão da responsabilidade social. In: COLOMBO, S. S.; RODRIGUES, G. M. Desafios da gestão universitária contemporânea. Porto Alegre: Artmed, cap. 18, p. 337-361, 2011.

COATES, $B$. A. Females as transformational leaders: Does gender make a difference? Doctoral dissertation, Capella University, Phoenix, US, 2010.

CONDE, F. G. A. Análisis sociológico del sistema de discurso. Cuadernos Metodológicos, 2009.

CONNELL, R. W. Gender and Power: Society, the Person and Sexual Politics. Stanford, California: Stanford University Press,1987.

CONNELL, R. W. Masculinities: Knowledge, power and social change. Berkely/Los Angeles: University of California Press, 1995.

CONNELL, R. W. Understanding men: gender sociology and the new international research on masculinities. In: SKELTON, C., FRANCIS, B. Y SMULYAN, L. (Eds.) The $S A G E$ handbook of gender and education, Londres: SAGE Publications, 2006.

COVERMAN, S.; SHELEY, J. F. Change in Men's Housework and Child-Care Time 19651975. Journal of Marriage and the Family, v. 48, n. 2, p. 413-422, 1986.

CULLEN, P. A. Universidades para el siglo XXI. Buenos Aires: edUTecNe, 2009.

DELORS, J. (Coord.) Educação: um tesouro a descobrir; Relatório para a UNESCO da Comissão Internacional sobre educação para o século XXI. São Paulo: UNESCO, Ed. Cortez, 1999.

EAGLEY, A. H. Sex differences in social behavior: a social interpretation. Hillslade, NJ: Lawrence Erlbaum, 1987.

GOETZ, A. M. National Women's Machinery: State-Based Institutions to Advocate for Gender Equality. In: RAI, S. (Ed.) Mainstreaming gender, Democratizing The State? Institutional Mechanisms for the Advancement of Women. Manchester, United Nations and Manchester University Press, p. 69-95, 2003. 
GODOI, C. K.; MELLO, R. B. de; SILVA, A.B. da. Pesquisa qualitativa em estudos organizacionais: paradigmas, estratégias e métodos. São Paulo: Saraiva, 2006.

HUNTER, L. A; LEAHEY, E. Parenting and Research Productivity: New Evidence and Methods. Social Studies of Science, v.40, n.3, p. 433-451, 2010.

IBAÑEZ, J. Más allá de la Sociología. El grupo de discusión, teoría y crítica. Madrid: Siglo XXI, 1979.

KAUFMAN, R. R.; CHEVAN, J. Y. The Gender Gap in Peer-Reviewed Publications by Physical Therapy Faculty Members: A Productivity Puzzle. Phisycal Therapy, v. 91, n. 1, p. 122-131, 2012.

KNIGHTS, D.; RICHARDS, W. Sex discrimination in UK academia. Gender, Work and Organization, v.10, n.2, p. 213-238, 2003.

LÓPEZ, C. B. A.; VERDUGO, M. S. R.; ZAZUETA, M. L. U. La segregación académico/laboral de las profesoras de la Universidad Autónoma de Sinaloa. X Congreso Nacional de Investigación Educativa, área 10: Interrelaciones educación-sociedad, 2009.

LÓPEZ-SEGRERA, F. La educación superior en el mundo y en América Latina y el Caribe: principales tendencias. In: DOS SANTOS, T. (Ed.). América Latina y el Caribe: Escenarios posibles y políticas sociales. Montevideo: UNESCO, ROSTLAC. 2011.

MÓSESDÓTTIR, L. Gender (In) equalities in the knowledge Society. Gender, work and Organization, v.18 n.1, p. 30-47, 2011.

NETTLES, M. T.; PERNA, L. W.; BRADBURN, E. M. (Eds.) Salary, Promotion, and Tenure Status of Minority and Women Faculty in US Colleges and Universities. Washington, DC: National Center for Education Statistics, n. 173, 2000.

ONU - ORGANIZAÇÃO DAS NAÇÕES UNIDAS. Declaração Mundial sobre a Educação Superior no Século XXI: Visão e Ação,1998. Disponível em: http://www.unesco.org/education/educprog/wche/declaration_spa.htm\#declaration.

ORTI, A. La apertura y el enfoque cualitativo o estructural: la entrevista abierta y la discusión de grupo. In: GARCIA FERRANDO, M; IBAÑEZ, J; ALVIRA, F. El análisis de la realidad social. Métodos y técnicas de investigación social. Madrid: Alianza Editorial, 1989.

OSBORN, M.; REES, T.; BOSCH, M.; EBELING, H.; HERMANN, C.; HILDEN, J.; MCLAREN, A.; PALOMBA, R.; PELTONEN, L.; VELA, C.; WEIS, D.; WOLD, A. Report on Science Policies in the European Union: Promoting Excellence through Mainstreaming Gender Equality. ETAN Expert Working Group on Women and Science, Brussels: European Commission, 2000.

PATTON, M. Qualitative Research e Evaluation Methods. Londres: Sage Publications, 2002. 
PÉTURSDÓTTIR, M. G. Within the Aura of Gender Equality: Icelandic work cultures, gender relations and Family responsability. Reassessing the Nordic Welfare ModelInternational Conference Oslo, Norway, 21-22 August, 2012.

POPE, C.; MAYS, N. Qualitative research: reaching the parts other methods cannot reach. British Medical Journal, v. 311, p. 42-45, 1995.

RAPOPORT, R.; BAILYN, L.; FLETCHER, J.; PRUITT, B. Beyond Work-Family Balance: Advancing Gender Equity and Workplace Performance, San Francisco: Jossey-Bass, 2002.

RICCI, R. A peculiar Produção Intelectual do Brasil Recente. Revista Espaço Académico, n.100, 2009.

RIMASHEVSKAIA, N. Gender Stereotypes and the Logic of Social Relations. Russian Social Science Review, v. 49, n. 3, p. 35-48, 2008.

RODRIGUES, E. O lugar do gênero, dos homens e das mulheres na sociologia portuguesa: uma análise a partir da Associação Portuguesa de Sociologia. Centro de Investigação e Estudos de Sociologia-CIES, Working Papers n. 64, 23 p., 2009.

ROLIN, K.; VAINIO, J. Gender in Academia in Finland: Tensions between Policies and Gendering Processes in Physics Departments. Science Studies, v. 24, n. 1, p. 26-46, 2011. RUBIN, G. El tráfico de mujeres: notas sobre la economía política del sexo. In: LAMAS, M. (Comp.) El género: la construcción cultural de la diferencia sexual. México:

Porrúa/Programa Universitario de Estudios de Género-UNAM, 1996.

RUEDA, L. Análisis del discurso: manual para ciencias sociales. Barcelona: Editorial OUC, 2003.

SÁNCHEZ-HERRERO, S. A. La importancia de la perspectiva de género en la psicología del ocio. Anales de Psicología, v.24, n.1, p.64-76, 2008.

SÁNCHEZ-HERRERO, S. A.; SANCHEZ-LÓPEZ, M. P.; DRESCH, V. Hombres y trabajo doméstico: Variables demográficas, salud y satisfacción. Anales de Psicología, v.25, n.2, p.299-307, 2009.

SANTOS, B. S. Da ideia de universidade a universidade de ideias. In: SANTOS, B. S. Pela Mão de Alice: o social e o político na pós-modernidade. Porto: Afrontamento, p. 187-233, 1994.

SOULET, M. Traces et intuition raisonnée. In: PAILLE, P. La Méthodologie qualitative. Postures de recherché et travail de terrain. Paris: Armand Colin, 2006.

VERLOO, M.; LOMBARDO, E. Contested Gender Equality and Policy Variety in Europe: Introducing a Critical Frame Analysis Approach. In: VERLOO, M. (Ed.) Multiple Meanings of Gender Equality. A Critical Frame Analysis of Gender Policies in Europe. Budapest: CEU Press, p. 21-49, 2007. 
WORLD BANK. Igualdade de gênero e Desenvolvimento. Relatório sobre o Desenvolvimento mundial de 2012. 62 p., 2011. Disponível em: www.worldbank.org XIE, Y.; SHAUMAN, K. A. Sex Differences in Research Productivity: New Evidence about an Old Puzzle. American Sociological Review, v. 63, n. 6, p. 847-870, 1998. 